\title{
O ENSINO DA TEORIA DA EVOLUÇÃO EM ESCOLAS DA REDE PÚBLICA DE SENHOR DO BONFIM: análise da percepção dos professores de Ciências do Ensino Fundamental II
}

\author{
Camila Laranjeira Costa de Oliveira' \\ Maria Cilene Freire de Menezes² \\ Olívia Maria Pereira Duarte 3
}

\section{RESUMO}

Embora a Teoria da Evolução seja um tema de grande importância para a compreensão de assuntos relacionados às diversas áreas das ciências biológicas, é notória a dificuldade de compreensão do tema, principalmente no âmbito escolar. Dessa forma, o objetivo deste trabalho consiste em investigar a abordagem do ensino dessa teoria por professores de ciências dos anos finais ( $6^{\circ}$ ao $9^{\circ}$ ano) do ensino fundamental da rede pública do município de Senhor do Bonfim - Bahia. Também se buscou identificar as concepções dos professores sobre a temática e levantar os possíveis obstáculos ao ensino da Teoria da Evolução no ensino fundamental. A pesquisa caracteriza-se como qualitativa, utilizando-se como instrumentos de coleta de dados questionários compostos por perguntas fechadas e abertas. Os resultados demonstraram limitações no ensino da teoria evolutiva, relacionadas à formação inicial dos docentes; à existência de barreiras para o entendimento da teoria da evolução diante de concepções criacionistas e à falta de entendimento acerca do sistema de teorias evolutivas por parte dos docentes. Essas observações indicam que o ensino da Teoria da Evolução no ensino fundamental é deficiente e pode contribuir para a formação de concepções equivocadas acerca do tema.

Palavras-chave: Ensino de Ciências. Concepções. Teoria da Evolução.

\footnotetext{
1 Licenciada em Ciências da Natureza pela Universidade Federal do Vale do São Francisco (UNIVASF). Discente do curso de especialização em Divulgação da Ciência, da Tecnologia e da Saúde pela Fundação Oswaldo Cruz (COC\FIOCRUZ-RJ). E-mail: camilalaranjeiracosta@gmail.com.

2 Doutora em Ensino, Filosofia e História das Ciências pela Universidade Federal da Bahia (UFBA). Docente do Colegiado de Ciências da Natureza - Universidade Federal do Vale do São Francisco. Senhor do Bonfim-BA. E-mail: cilene.menezes@univasf.edu.br.

3 Doutora em Genética e Biologia Molecular pela Universidade Estadual de Santa Cruz (UESC). Docente do Colegiado da Licenciatura Interdisciplinar em Ciências da NaturezaUniversidade Federal do Sul da Bahia-Porto Seguro - BA. E-mail: olivia.duarte@ufsb.edu.br
} 


\title{
THE EVOLUTION THEORY TEACHING IN PUBLIC SCHOOLS NETWORK: analysis of
}

\author{
the science teachers' perception in elementary school
}

\begin{abstract}
Although the Theory of Evolution is a subject of great importance for the understanding of subjects related to the different areas of the biological sciences, it is notorious the difficulty of understanding it, especially in the school context. Thus, the objective of this work was to investigate the teaching approach of this theory by science teachers in the final years (6th to 9th grade) of the public elementary school in "Senhor do Bonfim" city, Bahia State. It also aimed at identifying the teachers' conceptions on the subject and to raise the possible obstacles to the teaching of Evolution Theory in elementary school. The research is characterized as qualitative, using questionnaires composed of closed and open questions as instruments of data collection. The results showed limitations to the teaching of the evolutionary theory related to the teachers' initial formation; barriers to the understanding of the Evolution Theory in the face of creationist conceptions and the teachers' lack of understanding about the system of evolutionary theories. These observations indicate that the theory of evolution in elementary education is deficient and can contribute to the formation of misconceptions about the subject.
\end{abstract}

Keywords: Science teaching. Conceptions. Theory of Evolution.

\section{ENSEÑANZA DE LA TEORÍA EVOLUCIÓN EN LAS ESCUELAS DE LA RED PÚBLICA DE SENHOR DO BONFIM-BA: análisis de la percepción de la ciencia maestros primaria II}

\section{RESUMEN}

Aunque la teoría de la evolución es un tema importante para la comprensión de las cuestiones relacionadas con las diversas áreas de las ciencias biológicas, se observa la dificultad de comprensión de la materia, especialmente en las escuelas. Por lo tanto, el objetivo de este estudio es investigar el enfoque de la enseñanza de esta teoría por los profesores de ciencias de los últimos años $\left(6^{\circ}\right.$ a $9^{\circ}$ grado) de la educación primaria en las escuelas públicas en el municipio de Senhor do BonfimBA. Asimismo, se buscó identificar las concepciones de los profesores sobre el tema y plantear las posibles obstáculos a la teoría de la enseñanza de la evolución en la escuela primaria. La investigación se caracteriza como cualitativo, utilizando cuestionarios como instrumentos de recolección de datos con preguntas cerradas y abiertas. Los resultados mostraron limitaciones a la enseñanza de la teoría de la evolución en relación con la formación inicial de los maestros; barreras para la comprensión de la teoría de la evolución antes vistas criacionistas e a falta de entendimento acerca do sistema de teorias evolutivas por parte dos docentes. Estas observaciones indican que la educación de la teoría de la evolución en la educación primaria es deficiente y puede contribuir a la formación de conceptos erróneos sobre el tema.

Palabras clave: Educación Ciencia. Conceptos. Teoría de la Evolución. 


\section{INTRODUÇÃO}

Em todas as civilizações, a origem da vida e o significado da existência dos seres vivos e de tudo que existe sempre foram questões que demonstraram preocupação para a humanidade. Ao longo do tempo, diferentes respostas foram recebidas na busca pela compreensão acerca da origem da vida, no passado a partir da religião e da mitologia que eram as únicas fontes de conhecimento, posteriormente surgiu o pensamento filosófico que propôs novas ideias e por fim o desenvolvimento da ciência (ANDRADE, 1994).

As convicções filosóficas foram profundamente abaladas por grandes concepções científicas como a teoria heliocêntrica e a teoria da evolução (BRANCO, 2004). A Teoria da Evolução, considerada a mais importante ideia científica jamais formulada, possui implicações que provocam amplas consequências filosóficas, políticas e ideológicas (MONOD, 1976).

A Teoria da Evolução das espécies cria discussão no ambiente acadêmico e no meio escolar e tem como característica que a diferencia das outras teorias, o caráter polêmico voltado para o tema, o qual envolve além dos conhecimentos científicos a subjetividade e as crenças das diversas culturas (MARQUES; ANJOS; BRANDÃO, 2012).

Charles Robert Darwin ocasionou uma verdadeira revolução científica diante do progresso na biologia evolutiva com a publicação do livro Origem das espécies em 1859. Além das contribuições científicas, Darwin levou muitas contribuições para o pensamento humano moderno, como a substituição de uma visão de mundo baseada em dogmas cristãos, por uma visão de mundo rigorosamente secular. Adicionalmente suas inovações conceituais levaram à substituição de conceitos refutados que afetaram de alguma forma, componentes do sistema humano de crenças (MAYR, 2005).

A biologia evolutiva contribui para a sociedade no atendimento às suas necessidades e em inúmeras contribuições e extensões para além da área das ciências biológicas. Alguns exemplos referem-se à saúde humana, 
à agricultura e recursos renováveis, produtos naturais, gerenciamento e conservação ambiental e análise da diversidade humana (FUTUYMA, 2002).

Para Futuyma (2002), muitas aplicações potenciais da Biologia às necessidades da população não podem ser desenvolvidas nem exploradas sem a Evolução. O autor considera que nenhuma questão do ensino relacionado aos temas biológicos é mais urgente ou importante do que a comunicação da natureza, das implicações e aplicações da Evolução.

A evolução biológica deve ser vista como componente imprescindível para a adequada compreensão da maior parte dos conceitos e das teorias encontradas na área das ciências biológicas. Por isso não é adequado tratar a Evolução como apenas mais um conteúdo a ser abordado junto a quaisquer outros assuntos, haja vista que as ideias evolutivas têm papel fundamental na organização do pensamento biológico (MEYER; EL-HANI, 2005).

O reconhecimento da importância da Teoria da Evolução está expresso nos currículos educacionais das propostas oficiais de ensino. De acordo com os Parâmetros Curriculares Nacionais de Ciências Naturais, o destaque às explicações evolucionistas é evidente, e a aprendizagem dos diferentes conceitos está explícita nos conteúdos de cada ciclo do ensino fundamental (BRASIL, 1998).

Para Bizzo, Sano e Monteiro (2016) a Evolução não pode ser deixada como a última parte da Biologia a ser abordada, tanto na educação básica quanto no ensino superior.

Bizzo (1991) destaca que a abordagem de temas a partir do estudo da História das Ciências se faz importante para o ensino de ciências, essa estratégia permite ao professor promover a utilização de metodologias que aproximem o estudante do entendimento do progresso das teorias científicas, e dessa forma proporcionar aos estudantes conexões com as teorias e um entendimento coerente. A Teoria da Evolução possui um destaque dentro da História das Ciências que se inicia desde os primórdios da humanidade na busca de respostas relacionadas à existência humana. 
Dessa forma, o ensino da Teoria da Evolução pode proporcionar aos estudantes a contextualização histórica acerca do desenvolvimento das teorias científicas.

Para os Parâmetros Curriculares Nacionais o conhecimento sobre teorias anteriores contribui para a compreensão das concepções presentes, por isso a História da Ciência tem sido uma sugestão de ensino necessária, além de ser um conteúdo indispensável no aprendizado. O conhecimento prévio proveniente do ambiente social, construído independente do ambiente escolar nem sempre é considerado relevantes mas deve ser alvo especial de atenção nesse ambiente (BRASIL, 1998).

A Evolução é considerada um tema unificador e ocupa posição central dentro das ciências biológicas diante da sua importância para o entendimento dos mecanismos biológicos e das suas implicações às necessidades da sociedade. O entendimento acerca da Evolução é de grande importância para a compreensão nas diversas áreas das ciências biológicas, pois proporciona uma visão ampla (FUTUYMA, 2002).

Entretanto, alguns fatores dificultam a compreensão e o diálogo acerca de informações oferecidas pelo sistema de teorias evolutivas. Parte desses fatores está relacionada à falta de clareza dos pesquisadores da área em expressar o conhecimento acerca da Teoria da Evolução. Outras dificuldades referem-se à utilização de conceitos relacionados aos conhecimentos históricos e técnicos da biologia evolutiva, muitas vezes apresentados de forma incompleta, inapropriada e obscura (MARTINS; SANTOS; COUTINHO, 2012). Esses autores consideram que em consequência disso, o público leigo, especializado e os professores têm dificuldades em compreender a lógica do sistema de teorias evolutivas, especialmente por causa das incontáveis concepções equivocadas que são repetidas há décadas pelos livros, pelos meios de comunicação, e até mesmo por alguns professores e pesquisadores.

O processo de aprendizagem no ambiente escolar tem sido cada vez mais rodeado de obstáculos e barreiras que dificultam a compreensão dos 
mecanismos evolutivos. Muitos trabalhos têm evidenciado problemas no entendimento das teorias evolutivas (MONOD, 1976; SANTOS e CICILLINI, 2004; RIBEIRO e SANTOS, 2013; BRANCO, 2004; MARTINS, SANTOS e COUTINHO, 2012).

Conforme pesquisa realizada por Santos e Cicillini (2004), foi possível perceber diante dos relatos de professores que, nos anos iniciais do ensino fundamental professores priorizam o ensino de português e matemática, julgando serem estas disciplinas pré-requisito para que o estudante seja capaz de compreender outras disciplinas como ciências, história e geografia. Também nos primeiros anos do ensino fundamental, o tratamento de informações é comumente restrito ao senso comum, na justificativa de que os estudantes não possuem maturidade suficiente para aprender determinados conteúdos. O ensino de ciências é pouco valorizado e a predominância do método tradicional de ensino é justificada pelos professores como a melhor alternativa diante da falta de recursos na escola e as condições de trabalho.

Entretanto, conforme os PCN's nos anos iniciais do ensino fundamental através da ludicidade, de várias atividades, e da interação direta com os fenômenos, os alunos poderão construir conhecimentos científicos sem muita complexidade conforme seu desenvolvimento cognitivo. De acordo com o conhecimento construído nesses primeiros ciclos e nos anos finais do ensino fundamental os estudantes estarão aptos para sistematizar conhecimentos científicos com maior abrangência (BRASIL, 1998).

No âmbito da modalidade de ensino EJA (Educação de Jovens e Adultos), Ribeiro e Santos (2013) discutem que a divulgação científica relacionada à Genética e a Biologia Molecular por profissionais não especializados na área, tem contribuído para a formação de conceitos equivocados que prejudicam a compreensão de conceitos científicos e aceitação na sociedade. Os autores trazem a discussão sobre dificuldades na abordagem por parte dos professores e de compreensão por parte dos estudantes. 
Coutinho, Santos e Martins (2012) descrevem que aparecem com frequência ideias equivocadas envolvendo espécies atuais que sugerem direcionamento no processo evolutivo criando uma hierarquia entre as mesmas. Os autores citam como exemplo o uso de classificações equivocadas de alguns grupos taxonômicos ou espécies em primitivos, avançados, superiores e inferiores. Esta última ideia aparece com frequência no ensino médio e superior.

Apesar de todas as evidências apresentadas pelos evolucionistas, algumas opiniões, por motivações religiosas que se baseiam na hipótese fixista da criação, persistem em não aceitá-las e existe uma grande representação por parte de fiéis, principalmente na América do Norte (BRANCO, 2004).

Entre inúmeras questões acerca do tema, é importante começar pela identificação das concepções dos professores acerca da Teoria da Evolução, uma vez que, diante do seu papel de mediador entre o conhecimento e o estudante, a falta de compreensão dos docentes pode propiciar aos estudantes concepções equivocadas sobre o assunto.

Assim, o objetivo deste trabalho foi investigar como professores de ciências abordam a Teoria da Evolução nos anos finais ( $6^{\circ}$ ao $9^{\circ}$ ano) do ensino fundamental, da rede pública do município de Senhor do Bonfim Bahia. Bem como, identificar os possíveis obstáculos e eventuais dificuldades para o ensino do tema, e analisar a sua importância, assim como os tipos de recursos utilizados para a sua abordagem na concepção dos professores.

Para tanto, foi aplicada uma metodologia qualitativa para coleta e análise de dados, a qual permitiu constatar diversos fatores que dificultam o ensino e a aprendizagem da Teoria da Evolução.

\section{PROCEDIMENTOS METODOLÓGICOS}

De acordo com Weller e Pfaff (2011) no campo da educação as abordagens qualitativas são relevantes, não somente no desenvolvimento 
de pesquisas e teorias ou na avaliação de programas e políticas educacionais, mas também no processo de ensino/aprendizagem e durante a formação de futuros profissionais que irão atuar nesse campo.

A maior parte dos trabalhos em pesquisa qualitativa tem como principal fonte a análise de documentos e entrevistas (WELLER e PFAFF, 2011) Consequentemente de acordo com Gatti e André (2011) grande parte das pesquisas nos últimos anos está centrada no sujeito, cujo objetivo é investigar opiniões, percepções, representações, emoções e sentimentos de professores, alunos, gestores escolares, pais de alunos, sobre um determinado tema ou questão.

Gatti e André (2011) defendem que as abordagens qualitativas para a pesquisa e o conhecimento em educação no Brasil precisam adensar sua capacidade explicativa. Visto que a identificação de padrões, dimensões e relações ou mesmo a construção de modelos explicativos, além de serem compatíveis com o estudo de fenômenos microssociais, constituem uma etapa essencial à construção/reconstrução de teorias e à aplicação a outros contextos.

Dessa forma, esta pesquisa caracterizou-se como qualitativa, exploratória e explicativa tendo como público-alvo 25 professores da disciplina de ciências dos anos finais do ensino fundamental de 13 escolas da Rede Pública, localizadas na zona urbana de Senhor do Bonfim (Bahia, Brasil) sendo três escolas estaduais e dez escolas municipais. A pesquisa ocorreu durante o período de outubro de 2014 a fevereiro de 2015.

Os professores foram convidados a participar como voluntários do trabalho, onde foram esclarecidos sobre os objetivos da pesquisa, registrando o entendimento acerca desta através do Termo de Consentimento Livre Esclarecido.

$O$ instrumento utilizado para coleta de dados constituiu-se num questionário semi-estruturado composto por 18 questões, fechadas, de múltipla escolha e abertas. Conforme Marconi e Lakatos (2010) questões abertas possibilitam respostas livres, a fim de emitir opiniões e utilizar 
linguagem própria. Questões fechadas e de múltipla escolha, visam proporcionar um questionário limiłado em extensão, uma vez que questionários longos tendem a causar desinteresse e exaustão ao entrevistado. Contudo manteve-se o cuidado para que as informações fossem suficientes.

As questões versavam sobre os dados gerais do entrevistado, como, gênero, idade e denominação religiosa, sua formação acadêmica, os aspectos profissionais e questões específicas acerca do ensino da Teoria da Evolução, tais como: a abordagem da Teoria da Evolução em sala de aula; as dificuldades ou não, na abordagem do tema e a importância da abordagem no ensino fundamental.

Os questionários foram entregues individualmente aos docentes para que respondessem em momento oportuno, marcando-se o reencontro em uma data escolhida pelo entrevistado, para a devolução dos mesmos.

As respostas de maior destaque foram transcritas literalmente, e, para não identificar o docente utilizamos as letras do alfabeto ao nos referirmos ao conteúdo das respostas.

\section{RESULTADOS E DISCUSSÃO}

Os resultados da análise dos 25 questionários demonstrou que a maioria dos docentes pertence ao gênero feminino (22), com idade entre 27 e 56 anos. A denominação religiosa predominante entre os professores foi a católica (17) seguida pela evangélica (3) e em menor frequência estão as denominações espírita (2); e umbanda. Adicionalmente 2 entrevistados não declararam possuir qualquer denominação religiosa.

Quanto à formação acadêmica inicial em nível de graduação, entre os professores participantes da pesquisa apenas 6 são licenciados em Ciências, os demais possuem licenciatura em outras áreas como, Ciências Biológicas (11), Pedagogia (5), Letras (2) e Educação Física (1). Ou seja, dos professores de ciências em exercício, 8 possuem formação inicial em áreas 
não afins, se tratando do ensino da Evolução Biológica, essa característica pode interferir na atuação docente. Em relação ao tempo de atuação dos docentes entrevistados verificou-se uma variação de 5 a 34 anos, conforme apresentado na Tabela 1.

TABELA 1 - Caracterização dos professores entrevistados quanto ao perfil social e acadêmico

\begin{tabular}{|c|c|}
\hline Variáveis & Descritores(n) \\
\hline Gênero & $\begin{array}{l}\text { Feminino (22) } \\
\text { Masculino (3) }\end{array}$ \\
\hline \multirow{5}{*}{ Idade } & $27-32$ anos (4) \\
\hline & $33-38$ anos (3) \\
\hline & $39-44$ anos (7) \\
\hline & $45-50$ anos (6) \\
\hline & $51-56$ anos (5) \\
\hline \multirow{5}{*}{ Denominação religiosa } & Católica (17) \\
\hline & Evangélica (3) \\
\hline & Espírita (2) \\
\hline & Umbanda (1) \\
\hline & Não declarante (2) \\
\hline \multirow{5}{*}{ Curso de graduação cursado } & Ciências Biológicas (11) \\
\hline & Ciências Naturais (6) \\
\hline & Educação Física (1) \\
\hline & Letras (2) \\
\hline & Pedagogia (5) \\
\hline \multirow{4}{*}{ Tempo de atuação no ensino básico } & $\begin{array}{l}5 \text { a } 10 \text { anos (2) } \\
11 \text { a } 16 \text { anos (10) }\end{array}$ \\
\hline & 17 a 22 anos (9) \\
\hline & 23 a 28 anos (3) \\
\hline & 29 a 34 anos (1) \\
\hline \multirow{14}{*}{ Disciplinas ministradas } & Ciências (6) \\
\hline & Ciências e Biologia (3) \\
\hline & Ciências, Biologia e Geografia (1) \\
\hline & Ciências, História e Cultura Afro (1) \\
\hline & Ciências e Educação Física (4) \\
\hline & Ciências e Inglês (1) \\
\hline & Ciências e Religião (1) \\
\hline & Ciências e Geografia (1) \\
\hline & Ciências e Matemática (1) \\
\hline & Ciências e Língua Portuguesa (2) \\
\hline & $\begin{array}{l}\text { Ciências, Biologia, Química e Cultura } \\
\text { Afro(1) }\end{array}$ \\
\hline & Ciências, Química e Educação. Física (1) \\
\hline & Ciências, História, Arte, Cultura Afro, \\
\hline & Ensino Religioso e Geografia (1) \\
\hline
\end{tabular}

Fonte: Questionários de pesquisa de campo, 2014 - 2015

No discurso dos docentes a insegurança para atuar e algumas limitações para a prática da docência em ciências foram expressas 
relacionando a formação inicial dos docentes em exercício, conforme a fala do entrevistado:

"Não sou habilitado na área de ciências, pois fiz graduação em letras - inglês. Dessa forma me sinto inseguro para atuar" (Docente A).

Em relato de outro docente as dificuldades também são associadas à sua formação:

"[...] as dificuldades são percebidas devido a formação, o que me leva a pesquisar mais durante o planejamento, mas não vejo a pesquisa como ponto negativo, pelo contrário. Falta de conhecimento aprofundado na área (devido a formação), falta de recursos no ambiente escolar" (Docente K).

Também verificamos que além da disciplina de ciências ministrada pelos docentes, 19 deles lecionam outras disciplinas, entre elas biologia, química, matemática, história, geografia, língua portuguesa, ensino religioso, inglês, educação física, cultura afrobrasileira e artes (Tabela 1). Esta circunstância evidencia um desvio entre a formação e a atuação docente, prática que resulta em consequências negativas para o processo de ensino e aprendizagem e também para o planejamento do professor diante das atividades diversas.

Damaceno Filho, Góes e Rocha (2011) mostram a distorção entre a formação e a atuação de professores licenciados atuantes nas escolas da rede pública, em Itabuna na Bahia. Conforme analisado pelos autores, a busca pela complementação da carga horária, as motivações relacionadas a questões econômicas, e a falta de professores na rede de ensino contribui para o desvio entre a formação e a atuação docente. A prática conhecida 
na área da administração educacional por "alocação de professor" resulta em consequências negativas para o processo de ensino-aprendizagem, na maioria das vezes ocasionada pela falta de embasamento teórico do docente que se traduz na prática de reprodução do livro didático. Considera-se importante que o professor compreenda claramente os mecanismos da Evolução Biológica, caso contrário o ensino desse tema consequentemente enfrentará problemas (SILVA; ANDRADE; CALDEIRA, 2010).

Verificou-se a falta de compreensão a respeito da Evolução como teoria científica, o que constitui uma barreira à sua aceitação, por vezes associada a uma concepção criacionista registrada no discurso do docente, transcrito a seguir:

"Por ser evangélico, encontro algumas dificuldades em tratar de um assunto tão polêmico numa sala de aula. Não vejo como abordar um assunto sem fazer uso da verdadeira fonte da informação, que é a Bíblia, pois uma vez tentei dar aulas de religião usando uma Bíblia e fui censurado. Por isso, prefiro não entrar nesse tema em sala de aula. Todo ser humano tem direito de saber sobre sua origem e seu destino, e Deus, o criador, deixou todas as informações necessárias, mas se eu não posso usar as informações que Ele mesmo deixou, eu me reservo o direito de não manter no ou levar alguém ao engano. Não sou nenhum teólogo, mas aprendi na Bíblia que fui criado por um Deus que me ama e à Sua imagem e semelhança e eu tenho certeza que o meu Deus, apesar de ser criador de todos os seres, Ele não é um macaco. Creia nisto, Deus ama você, creia Nele!" (DOCENTE B).

No extrato da entrevista transcrito anteriormente, O docente B 
manifesta claramente a intenção de que seja trabalhado o tema Evolução ancorado na concepção criacionista. De acordo com Silva, Andrade e Caldeira (2010), durante o processo de construção do conhecimento pelo estudante, se difundem ideias incertas que promovem confusões conceituais. Dessa forma, não é apropriado que o docente, mediador do conhecimento construído pelo estudante, trabalhe ideias evolutivas se baseando em concepções divergentes da concepção científica.

Conforme Carneiro (2004), estudantes e professores possuem uma visão equivocada sobre a Evolução Biológica, podendo ter sua origem principalmente na visão Criacionista, que explica a origem da vida na Terra a partir dos atos da Criação. A autora descreve que alguns estudos têm indicado fatores que dificultam o processo de aprendizagem das teorias evolutivas. A forte influência religiosa, os equívocos conceituais, e a falta de conexão dos temas evolutivos com os demais temas das ciências biológicas, comprometem professores e estudantes no entendimento dos mecanismos evolutivos.

A influência religiosa foi considerada por 5 professores como principal barreira para a compreensão da Evolução por parte dos estudantes:

"A principal dificuldade é para eles compreenderem os aspectos científicos que sustentam a teoria, já que a maioria tem seus preceitos religiosos sobre a vida" (DOCENTE J).

Nas escolas, os estudantes influenciados pelas religiões tendem a ter um pensamento criacionista e não aceitam o conhecimento científico sobre a Evolução, ao tratar desses assuntos é como se confrontasse com as concepções bíblicas, sendo, por eles consideradas inquestionáveis (MARTINS; SANTOS; COUTINHO, 2012). Esta situação corrobora com as dificuldades relatadas pelo professor: 
"Muitas vezes os alunos já trazem de casa conceitos que são aprendidos com seus familiares, sobre 'origem do mundo', 'a criação do homem', e acaba sendo difícil fazer com que ele passe a ter pensamentos reflexivos sobre a 'evolução'" (DOCENTE L).

Em outro relato, torna-se evidente a visão distorcida da Evolução Biológica por parte das concepções prévias dos estudantes, segundo relato do professor:

"Os estudantes colocam o homem como referencia da evolução, eles acham que a evolução é aquele processo que transforma um macaco em um homem" (DOCENTE U).

Segundo Carneiro (2004), a explicação de que o homem se originou de macacos é mais simples do que a explicação científica em que ambos os seres têm um ancestral comum.

Além das crenças religiosas, também foram mencionados outros fatores atribuindo as dificuldades no ensino de Evolução aos estudantes, como, indisciplina, o uso indevido de aparelhos tecnológicos, a falta de concentração, o déficit de aprendizagem, e até concepções prévias consideradas errôneas. Além disso, a complexidade do tema, os conceitos científicos abstratos e a quantidade de termos acerca dos mecanismos evolutivos foram apontados por 3 professores como fatores que dificultam o entendimento dos estudantes.

Krasilchik (2008) considera que a falta de concentração dos estudantes nas aulas, precisamente nas relacionadas às ciências biológicas, ocorre devido à terminologia usada pelo professor, muitas vezes desconhecidas pelos estudantes, ou porque são atribuídos aos termos diferentes significados. Tal acontecimento é relatado pelo entrevistado Docente I como uma dificuldade no ensino do tema: 
"Os alunos ainda não conseguem compreender conteúdos tão abstratos, também não conseguem se concentrar para ouvir etc" (DOCENTE I).

A preocupação em memorizar nomes diante do vasto vocabulário usado pelos professores em suas aulas, ainda é uma preocupação por parte dos estudantes. Às vezes são utilizados muitos termos de forma desnecessária e que apenas sobrecarregam os estudantes com informações inutilizáveis posteriormente (KRASILCHIK, 2008).

Ainda quanto à abordagem do tema Evolução, 3 professores declararam não sentir dificuldades em trabalhar o tema em sala de aula, em um dos casos as discussões proporcionadas pelo tema ainda foram vistas de forma positiva:

"Quando abordamos astronomia, formação do planeta Terra, falar que somos poeira de estrelas, levanta-se questionamentos que aborda religiões, mas há um debate interessante, gosto de questionar informalmente: 'viemos do macaco?'. Fazendo o aluno refletir e pesquisar" (DOCENTE V).

Por outro lado, verificou-se que durante a abordagem da Evolução no ensino de ciências, os estudantes podem manter-se inativos, evidenciando a falta de integração às aulas, já que dependendo da abordagem do professor, o tratamento do tema tende a proporcionar a participação dos estudantes diante das suas concepções prévias. Em relato:

[...] Os alunos que passaram por mim durante todos os anos que leciono, quase não questionam. Dessa forma os conteúdos são passados sem grandes polêmicas (DOCENTE G). 
O comportamento não atuante dos estudantes não é considerado favorável ao ensino, segundo Krasilchik (1987) o comportamento passivo dos estudantes ocorre em razão do ensino de forma expositiva, livresca e impositiva, evidenciando características desfavoráveis ao ensino das ciências. A autora ainda ressalta que é importante destacar que mesmo que os estudantes estejam em atividades envolvendo a prática e a dinâmica, a passividade intelectual pode persistir. Para que ocorra o aprendizado em ciências, além dessas atividades é necessária a formação de concepções próprias, sendo essencial que cada um dos estudantes esteja de fato envolvido no estudo dos assuntos abordados.

Considerando que existem dificuldades em ministrar aulas sobre 0 tema Evolução, recursos escolares como, material didático, o espaço físico, e $\mathrm{o}$ apoio pedagógico foram apontados por 5 docentes como fatores que proporcionam limitações para suas aulas:

\begin{abstract}
"Ambiente inadequado; na maioria das vezes o material tem que ser providenciado pelo professor (falta de recursos na escola) [...]" (DOCENTE H).
\end{abstract}

Em relação aos recursos utilizados na escola, verificou-se que o livro didático possui papel indispensável em sala de aula, mas que a dependência por esse recurso pelo professor pode trazer consequências negativas:

\begin{abstract}
"A grande dificuldade é pouco abordagem, ou quase nenhuma dos livros didáticos que chegam e precisamos trabalhar. [...] precisamos abordar os conteúdos necessários para a série, e o tempo é curto [...]" (DOCENTE C).
\end{abstract}

Santos e Cicillini (2004) comentam que, comumente os professores da 
rede pública de ensino estão subordinados a colocar em prática as propostas de ensino anteriormente elaboradas. Existe assim o impasse de poder ou não elaborar e colocar em prática livremente suas aulas. Limitamse, assim, a livros didáticos e/ou propostas e planos de ensino já elaborados, que muitas vezes não envolvem a realidade dos estudantes e do ambiente de ensino.

É sabido por muitos professores que a metodologia de ensino tradicional é ineficiente, porém, muitos ainda a utilizam com a defesa de que outros métodos são de difícil aplicação em virtude do despreparo, falta de estímulo e apoio por parte da escola e do meio social (SANTOS; CICILLINI, 2004).

Verificou-se que outras fontes são utilizadas pelos professores para enriquecer as aulas, os vídeos e textos foram mencionados por 22 professores, seguido da lousa, utilizada por 19 professores e da apresentação de slides por 15 professores. De acordo com Krasilchik (2008) grande parte das informações no ensino de biologia é alcançada através da observação, assim os recursos audiovisuais são reconhecidos por possuir um potencial.

Os jogos foram apontados como recurso utilizado nas aulas por 5 professores e apenas um professor mencionou a utilização de documentários. Sendo um dado significativo, vale destacar que os jogos didáticos favorecem o ensino e a aprendizagem de conceitos de difícil compreensão devido ao nível de abstração e complexidade, além de promover a interação em sala de aula (CAMPOS; BARTOLOTO; FELícIO, 2003).

Constatou-se que aulas práticas não são realizadas durante a abordagem do tema sobre a Teoria da Evolução por 15 dos professores. Estes alegaram a deficiência no espaço físico e a falta de materiais como justificativa para a não realização da prática. Em dois casos distintos, a não realização de atividades práticas esteve relacionada à dificuldade em utilizar o conteúdo teórico em aulas práticas, e outro professor relatou ser a falta de conhecimento na área, como mostra os relatos: 
"Muitas vezes torna-se complicado converter alguns conteúdos teóricos em aulas práticas, também a dificuldade de conseguir materiais etc." - (DOCENTE I). "Falta de conhecimento aprofundado na área (devido a formação), falta de recursos no ambiente escolar" (DOCENTE K).

Para Bizzo (2002) através da prática o estudante pode verificar seus conhecimentos e muitas vezes sendo levados a rever seus pensamentos, por isso é importante que 0 professor perceba a importância da experimentação no ensino de ciências. Contudo, Santos e Cicillini (2004) destacam que a experimentação é muitas vezes associada pelos professores como sendo atividades realizadas em laboratórios bem equipados, sendo essa uma concepção equivocada que impede que sejam desenvolvidas as atividades práticas.

Ainda assim, 10 professores realizam as práticas fora dos laboratórios, devido a sua inexistência, explorando espaços como a própria sala de aula e espaços externos como, por exemplo, o próprio jardim da escola, envolvendo a utilização de materiais alternativos como sucata e materiais de baixo custo, e também em um caso materiais cedidos pela escola. Como mostra o relato:

"Não temos laboratório de Ciências, portanto, as aulas práticas são feitas na biblioteca, na sala de ciências, aulas campo no bairro, na UNIVASF" - (DOCENTE D).

Verifica-se neste relato, o reconhecimento de uma parceria entre a universidade e a escola, resultado da interação dos trabalhos realizados principalmente através do PIBID, como uma possibilidade alternativa à falta de estrutura das escolas.

É possível identificar que o ensino de ciências pode ser ministrado sem 
laboratórios, contudo as aulas práticas em laboratórios podem contribuir para o trabalho docente, propiciando aos estudantes a oportunidade de utilizar um local onde possam desenvolver atividades avançadas como projetos de pesquisas (KRASILCHIK, 1987).

Relacionado à importância da abordagem da Teoria da Evolução no ensino fundamental, nenhum professor participante mencionou a dimensão da Evolução como tema central para o entendimento dos mecanismos biológicos nem suas contribuições para as necessidades da sociedade. Dois entrevistados responderam à questão citando apenas o fato do tema proporcionar a reflexão e a manifestação das ideias por parte dos estudantes.

Foi atribuída por 21 entrevistados como justificativa para a importância do ensino do tema, a compreensão do surgimento da vida na Terra, as transformações e origens de novas espécies, a diversidade da vida na Terra, e as teorias científicas, assuntos esses pertinentes aos conteúdos abordados no ensino fundamental.

Conforme os Parâmetros Curriculares Nacionais, no $6^{\circ}$ e $7^{\circ}$ ano do ensino fundamental, podem ser introduzidos a problemática sobre a origem da vida e as explicações para a diversidade biológica. No $8^{\circ}$ e $9^{\circ}$ ano 0 estudo das diferentes teorias da evolução poderá ser evidenciado, em ocasião, a comparação entre a teoria lamarckista e darwinista poderá proporcionar discussões sobre os métodos científicos (BRASIL, 1998).

A preocupação em contemplar os conteúdos programáticos escolares pôde ser evidenciada na afirmação de 2 professores que justificam a importância do ensino do tema como mostra o relato do Docente $\mathrm{M}$ :

\footnotetext{
"É importante, porém, precisamos abordar os conteúdos necessários para a série, e o tempo é curto, não esquecendo também da dificuldade que eles trazem" (DOCENTE M).
} 
Em outro caso, as orientações apresentadas pelos Parâmetros Curriculares Nacionais (PCN) foi utilizada como a única justificativa para a importância da abordagem do tema:

"Pois trata de um conteúdo pertinente à grade curricular nacional do $7^{\circ}$ ano, não podendo deixar de ao menos ser abordado de maneira sucinta" (DOCENTE X).

Os relatos sugerem quase uma obrigatoriedade em abordar determinada quantidade de temas propostos em um curto espaço de tempo, essas informações corroboram com a pesquisa de Santos e Cicillini (2004), em que professores das séries iniciais do ensino fundamental, declaram seguir planos de ensino e se vêem com grande quantidade de conteúdos a serem trabalhados, em consequência os assuntos são trabalhados superficialmente em sala de aula, e comprometem os resultados quanto à aprendizagem dos estudantes que necessitam de tempo e cuidados.

\section{CONSIDERAÇÕES FINAIS}

No ensino da Teoria da Evolução a falta de embasamento teórico no exercício docente contribui para a formação de concepções equivocadas acerca do tema. As dificuldades por parte dos docentes em compreender 0 assunto, ocasiona a abordagem do tema Evolução de forma obscura e errônea levando os estudantes a formarem concepções equivocadas. Podemos afirmar que o desvio entre a formação inicial e a atuação docente, prejudica negativamente o processo de ensino e aprendizagem, como apontam Carvalho e Gil-Pérez (2011).

Concepções criacionistas sobre a origem da vida consistem em dificultar o ensino da teoria da Evolução, a religiosidade, sobretudo, limita ainda mais a abordagem do tema ao impedir as discussões sobre a origem 
da vida a partir de diferentes perspectivas. A falta de compreensão acerca do sistema de teorias evolutivas favorece a sua não aceitação.

Percebemos que os conteúdos são passados para os estudantes superficialmente, apenas com 0 intuito de se trabalhar os assuntos determinados nos livros didáticos seguindo um limite de tempo. Dessa forma, a aprendizagem do estudante é comprometida, diante da abordagem inapropriada dos conteúdos de Evolução por parte dos professores que promovem um ensino abstrato e de difícil compreensão para os estudantes.

A falta de recursos na escola é um fator que contribui com a predominância das aulas expositivas, sendo esse um motivo bastante questionado pelos professores. Porém, aproveitando os recursos disponíveis ao seu redor, 10 dos professores entrevistados buscam melhorias no ensino de Evolução, através da utilização desses recursos, desde a preparação das aulas, até o momento em que são ministradas.

Indicamos baseado neste estudo que a teoria da Evolução é de fato pouco compreendida pelos docentes, e a fragmentação do ensino pode ser evitada ao trabalhar a Evolução como um tema unificador dos conteúdos de ciências.

Conforme os Parâmetros Curriculares Nacional, no ensino fundamental devem ser considerados pelos estudantes a existência dos fósseis e os processos de formação destes, e ainda o conhecimento sobre as formas de vida extintas e outras muito antigas ainda existentes (BRASIL, 1998).

É importante que o aluno perceba através de incentivos do professor, a existência de mudanças evolutivas em todo o planeta, conhecendo sobre a grande variabilidade das populações, e compreendendo como a seleção natural atua. Em alguns casos, a seleção natural pode ser estudada por meio de vantagens adaptativas, a exemplo da camuflagem de algumas espécies no ambiente, sendo uma característica bastante evidente (BRASIL, 1998).

Conforme Bizzo e El-Hani (2009) resultados de estudos nacionais e internacionais acerca do ensino da Teoria da Evolução apontaram que os 
estudantes ao fim da educação básica, possuem um conhecimento sobre Evolução de forma bastante restrita. Para os autores, além do enfoque histórico necessário para que se desenvolva um verdadeiro entendimento sobre a Teoria da Evolução, o cuidado para que o tema não seja abordado apenas ao final da educação básica, evita a abordagem imprópria que deixa de cumprir o papel integrador efetivo no conhecimento biológico.

Para que sejam alcançados os objetivos do processo de ensinoaprendizagem é necessário que exista uma área para as discussões do pensamento científico que é solicitada pela Teoria da Evolução, e também do pensamento teológico, que resgata assuntos históricos da sociedade, por isso é imprescindível que o professor se prepare minuciosamente, estudando a fundo o tema Evolução (MARQUES, ANJOS e BRANDÃO, 2012).

Estas conclusões indicam a necessidade de intervenções no âmbito educacional, através da formação continuada de professores, para minimizar a problemática observada, contribuindo para a construção do conhecimento científico sobre a Teoria da Evolução e o maior diálogo entre as concepções dos estudantes e o conhecimento ensinado.

Novas estratégias de abordagem em sala de aula tem sido objeto de estudo para Bizzo, Sano e Monteiro (2016), com a finalidade de que sejam pensadas novas possibilidades para o ensino da Evolução no arranjo curricular da educação básica, apresentando contribuições para o posicionamento ativo dos estudantes frente a temas polêmicos como este. Na abordagem dos autores, a partir de acontecimentos históricos são criadas condições para que ocorra discussão ativa dos estudantes sobre o estatuto do conhecimento científico, o desenvolvimento de habilidades investigativas, a compreensão do método científico e a capacidade de posicionamento crítico diante de temas controversos.

Além das dificuldades para o ensino de evolução, expressas nos relatos dos docentes como, o engessamento do currículo, ou seja, a obrigatoriedade no cumprimento dos temas previamente estabelecidos, os problemas relativos à complementação de carga horária que coloca 
docentes para lecionar disciplinas distintas da sua área de formação, a falta de compreensão das teorias evolutivas, os dados representam uma espécie de fotografia do ensino de Evolução sob o olhar dos professores da rede pública do ensino fundamental II de Senhor do Bonfim, BA. No entanto, esse retrato pode ser observado também em outras realidades do interior do país, especialmente no estado da Bahia. Ao observar os dados da avaliação do PISA (2015) sobre a proficiência em ciências, observa-se que a Bahia é o penúltimo entre os estados da federação (BRASIL, 2016). Isso revela a importância de estudos dessa natureza para produzir diagnósticos situacionais, orientar propostas de formação continuada e estimular o desenvolvimento de políticas educacionais, entre outras ações.

\section{REFERÊNCIAS}

ANDRADE, R. M. História das Concepçōes sobre a Origem do Universo. São Paulo: Moderna, 1994.

BIZZO, N. M.V. Ciências: Fácil ou Difícil? 2. ed. São Paulo: Ática. 2002.

BIZZO, N. M. V. Ensino de Evolução e História do Darwinismo. Tese (Doutorado). Universidade de São Paulo - Faculdade de Educação - São Paulo: 1991.

BIZZO, N.; EL HANI, C. O arranjo curricular do ensino de evolução e as relações entre os trabalhos de Charles Darwin e Gregor Mendel. Filosofia e História da Biologia, v. 4, p. 235-257, 2009.

BIZZO, N. M. V.; SANO, P. T.; MONTEIRO, P. H. N. Registros escritos do conhecimento mútuo entre Gregor Mendel e Charles Darwin: uma proposta para trabalho em sala de aula com história contrafactual da ciência e didática invisível. Genética na Escola, v. 11, p. 294-309, 2016.

BRANCO, S. L. Evolução das espécies: o pensamento científico, religioso e filosófico. 2. ed. São Paulo: Moderna, 2004.

BRASIL, Secretaria de Educação Fundamental. Parâmetros Curriculares Nacionais: Ciências Naturais. Brasília: MEC /SEF, 1998.

BRASIL no PISA 2015: Análises e Reflexões sobre o desempenho dos estudantes brasileiros/OCDE Organização para a Cooperação e o Desenvolvimento Econômico. Fundação Santillana, São Paulo. 2016. Disponível em http://download.inep.gov.br/acoes_internacionais/pisa/resultados/2015/pisa 2015_completo_final_baixa.pdf. Acessado em: 17/04/2016 
CAMPOS, L. M. L.; BORTOLOTO, T. M.; FELÍCIO, A. K. C. A produção de jogos didáticos para o ensino de ciências e biologia: uma proposta para favorecer a aprendizagem. Caderno dos núcleos de Ensino, v. 3548, 2003.

CARNEIRO, A. P. N. A evolução biológica aos olhos de professores nãolicenciados. 2004. 119 f. Dissertação (Mestrado em Educação) - Centro de Ciências da Educação, Universidade Federal de Santa Catarina, Florianópolis, 2004.

CARVALHO, A. M. P. GIL-PÉREZ, D. Formação de professores de ciências: tendências e inovações. 10. ed. São Paulo: Cortez, 2011.

DAMACENO FILHO, A. R.; GÓES, L. M.; ROCHA, L. B. Distorção entre a formação e atuação do licenciado em Geografia nas escolas públicas de Itabuna (BA). Geografia (Londrina), Londrina, v. 20, n. 1, p. 129-145, jan./abr. 2011.

FUTUYMA, D. J. Evolução, ciência e sociedade. In: Congresso Nacional de Genética. Ed. Exclusiva. São Paulo: SBG. 2002.

GATTI, M.; ANDRÉ, M. Pesquisa A relevância dos métodos de pesquisa qualitativa em Educação no Brasil. In: WELLER, W.; PFAFF, N. Metodologia da Pesquisa Qualitativa em Educação: Teoria e Prática. $2^{a}$ ed. Vozes, Petrópolis, RJ, 336P. 2011

KRASILCHIK, M. O professor e o currículo das ciências. São Paulo: Editora Pedagógica e Universitária, 1987.

KRASILCHIK, M. Prática de ensino de biologia. 4 ed. São Paulo: EdUSP, 2008.

MARCONI, M. de A.; LAKATOS, E. M. Técnicas de pesquisa: planejamento e execução de pesquisas, amostragens e técnicas de pesquisa, elaboração, análise e interpretação de dados. 7 ed. São Paulo: Atlas, 2010.

MARQUES, C. S.; ANJOS, M. B.; BRANDÃO, M. I. O. Criacionismo ou evolucionismo? A teoria da evolução das espécies em debate no ensino de ciências. Ensino, Saúde e Ambiente, v. 5, n. 2, 2012.

MARTINS, R. P.; SANTOS, F. R.; COUTINHO, F. A. As dificuldades na compreensão do sistema de teorias evolutivas. Ciência em Tela. Vol. 5, número 1, 2012.

MAYR, E. Biologia, ciência única. São Paulo: Companhia das Letras, 2005.

MEYER, D.; EL-HANI, C. N. Evolução: o sentido da biologia. Unesp, 2005.

MONOD, J. L. A Propósito da Teoria Molecular da Evolução. In: HARRÉ, R. (Org). Problemas da revolução científica: incentivos e obstáculos ao progresso das ciências. Itatiaia - SP: EDUSP, p. 27-40. 1976.

RIBEIRO, R. A.; SANTOS, R. S. O processo de formação de professores de Biologia e a interferência das tecnologias e mídias no ensino de Genética e Biologia Molecular. ScireSalutis, Aquidabã, v.3, n.1, p.49-61,2013.

SANTOS, K. A.; CICILLINI, G. A. Concepções de Professoras sobre o Ensino de 
Ciências nas Séries Iniciais do Ensino Fundamental. Ensino em Re-Vista, v.11, n.1, jul.2002/jul.2003. 43-67. 2004.

SILVA, P. R.; ANDRADE, M. A. B. S.; CALDEIRA, A. M. A. Concepções de professores de Biologia a respeito da diversidade dos seres vivos: uma análise, considerando o desenvolvimento histórico das ideias evolucionistas. In: BASTOS, F. org. Ensino de ciências e matemática III: contribuições da pesquisa acadêmica a partir de múltiplas perspectivas [online]. São Paulo: Editora UNESP; São Paulo: Cultura Acadêmica, 2010. p. 147-167. Disponível em: $\quad<\mathrm{http} / / /$ books.scielo.org/id/3nwyv/pdf/bastos-9788579830860-08.pdf>. Acesso em: 15 jan. 2015.

WELLER, W.; PFAFF, N. Pesquisa Qualitativa em Educação: origens e desenvolvimento. In: WELLER, W.; PFAFF, N. Metodologia da Pesquisa Qualitativa em Educação: Teoria e Prática. $2^{a}$ ed. Vozes, Petrópolis, RJ, 336p. 2011.

Recebido em: Março de 2017 Aceito em: Junho de 2017 